\title{
IMAGE ANALYSIS COUPLED WITH A SEM-EDS APPLIED TO THE CHARACTERIZATION OF A PARTIALLY WEATHERED Zn-Pb ORE
}

\author{
Henrique Kahn ${ }^{(1)}$,Eliana S.Mano ${ }^{(1)}$ and Maria Manuela M. L. Tassinari( ${ }^{(1)}$ \\ (1) Univ. of Sao Paulo, Polytechnic School, Dept. of. Mining and Petroleum \\ Engineering-lct@poli.usp.br \\ Av. Prof. Mello Moraes, 2.373 - CEP 05508-900 - Phone: +5511 3818-5787 - FAX: \\ $+55113815-5785$
}

\begin{abstract}
The image analysis coupled with Energy Dispersive Spectrometry (EDS) analysis on a Scanning Electron Microscope (SEM) was applied to the characterization of a $\mathrm{Zn}$ and $\mathrm{Pb}$ ore as an efficient tool for mineral quantification and for the assessment of the degree of mineral liberation.

Screened size fractions of mineral particles were mounted on polished thin sections and, later on, analyzed by a SEM coupled with an EDS. This is important for the discrimination of different mineral phases, particularly when two minerals have similar average atomic numbers, such as willemite and pyrite. Two images per field were collected - backscattered electrons image and a multi-element X-ray dot mapping images. The results were utilized for quantification and liberation analysis of two valuable minerals in the ore sphalerite and galena.
\end{abstract}

Keywords: Image analysis, mineral quantification, liberation degree analysis 


\section{Introduction}

Mineral quantification and liberation degree (intergrowth) evaluations are a routine and a major issue on ore characterization for mineral processing. Liberation analysis is an essential data for mineral processing that shows the relative amount of individualized grains that derives from the valuable mineral phase ("free particles') available for physical concentration. These analyses can be performed manually by optical microscopy (OM) or scanning electron microscopy (SEM) in a very tiresome and exhaustive routine. Image analysis coupled with an OM or a SEM can perform these analyses resulting in more reliable and rapid outcomes $(1,2,3)$.

Since phase differentiation by OM coupled to an image analysis is not a usual and easy task, a digital SEM image is frequently used to solve more complex mineralogical associations. Special care must be taken regarding sample preparation and beam control $(2,3)$. Atomic number contrast from backscattered electrons (BSE) signal are primarily used for phase discrimination; however, when phases with a very similar average atomic number are present, X-ray information is the only possible tool that could be used to differentiate them.

This work presents an off-line image analysis routine applied to the characterization of a partially weathered $\mathrm{Zn}-\mathrm{Pb}$ ore. Six major mineral phases are presented and must be quantified as well as the liberation analysis, which must be performed in two valuable mineral phases - sphalerite, $\mathrm{ZnS}$, and galena, $\mathrm{PbS}$. The BSE image shows clearly six distinguishable gray levels, however one of them is related to two mineral phases with close atomic numbers - pyrite, $\mathrm{FeS}_{2}$ and willemite, $\mathrm{Zn}_{2} \mathrm{SiO}_{4}$ that could not be discriminated. These two particular phases could only be properly segmented by coupling additional information related to their chemical composition using X-ray data. Multielement Xray dot-mapping images acquired by an energy dispersive spectrometry (EDS) were considered for this purpose.

\section{Materials and Methods}

The study samples consisted of mineral particles from four closely screened fraction sizes mounted on polished thin sections. Special care was taken regarding the sample preparation to avoid the physical touch of particles as well as regarding the polishing surface quality.

BSE and X-ray dot images were obtained by a S440, Leo, coupled with an Isis300 EDS System, Oxford. X-ray dot-mapping images for up to 7 different elements were acquired by $\mathrm{S} 440$; each selected element was represented by a binary plane and by a specific gray level value. Both images, presenting 1024 by 768 pixels resolution, were processed off-line by Quantimet Qwin-Pro software, Leica, an image analysis system which operates under the same SEM PChardware.

In order to determine all the mineral phases, qualitative mineralogical work was first performed coupling X-ray diffraction data with a detailed SEM-EDS observation. Fig. 1 shows the BSE image of the particulate material of the size fraction between 20 and $37 \mu \mathrm{m}$. The major mineral phases are constituted essentially by sphalerite, galena, pyrite, willemite, quartz and dolomite; barite, apatite and ilmenite occur as trace minerals $(<1 \%)$ and were not discriminated by image analysis (others). 


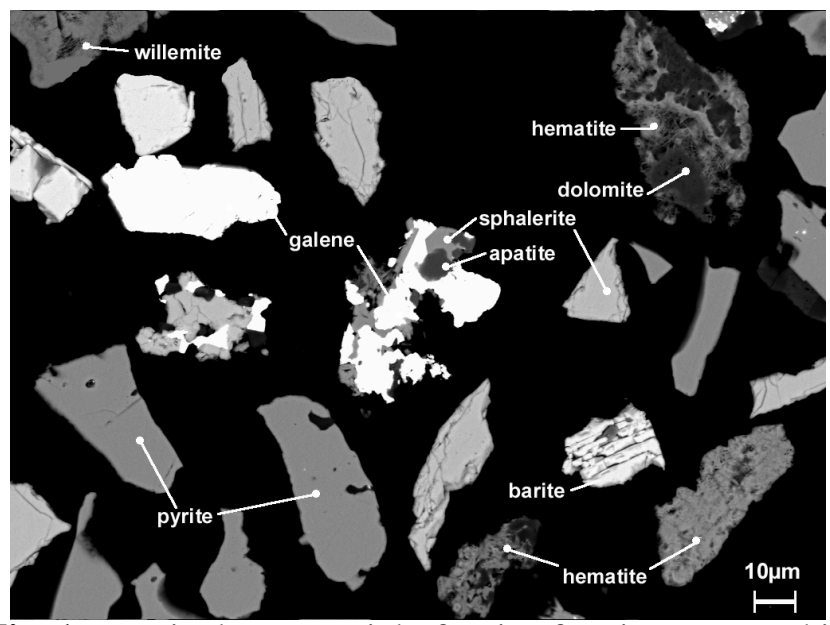

Fig. 1 - Particulate material of a size fraction mounted in a thin-polished section presenting the major mineral phases.

The second step comprised the acquisition of BSE and Xray dot-mapping images. Since the acquisition time for the dot images were relatively high, off-line image processing was chosen to assure a better SEM electron beam stability during the total acquisition period, which corresponds to almost 200 minutes for 30 fields per sample. Incident probe current, brightness and contrast levels were set to allow the acquisition of BSE and X-ray images with a good quality for further processing.

Because particle density per field is one of the major factors that directly affect the total processing time, an ideal compromise is required to optimize the acquisition time. The SEM magnification was adjusted for an average of 40 to 50 particles per field, a situation in which some particles may touch other particles. For this reason, the first step in image processing is to individualize these touching particles.

A relatively complex subroutine (2), summarized in the Fig. 2, was applied to discriminate the touching particles. Firstly, the detected image (Fig. 2a) was eroded (Fig. 2b), and then skeleton and prune operations were applied in order to separate the particles so they would not touch each other. Finally applying outline followed by close and open operations to the particles resulted in the dark lines of potential touching areas (Fig. 2d). These lines were subtracted from detected image (Fig. 2a) by logical operation, resulting in the final binary image of particles to be measured. 


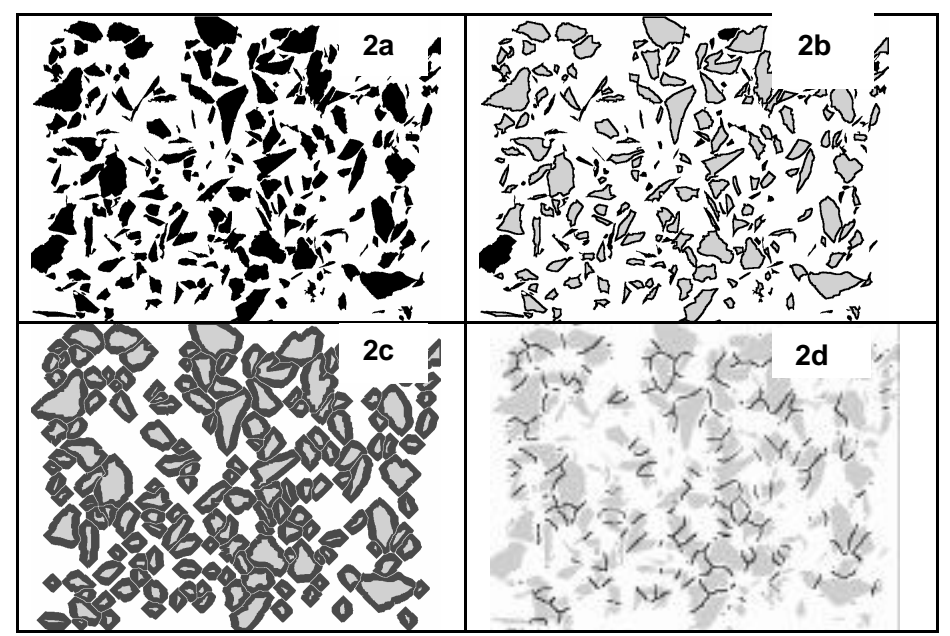

Fig. 2 - Separation of touching particles.

An image analysis routine was developed in order to discriminate the mineral phases and, later $\mathbf{m}$, to perform modal and mineral liberation analysis. Detection, identification and segmentation of the phases are the most complex issues, and the routine should process a gray scale image plus external inputs as the X-ray dot image.

Gray level threshold from the BSE image allowed discriminating up to 6 binary planes - galene, sphalerite, "pyrite+willemite", hematite, quartz and dolomite (Fig. 3).

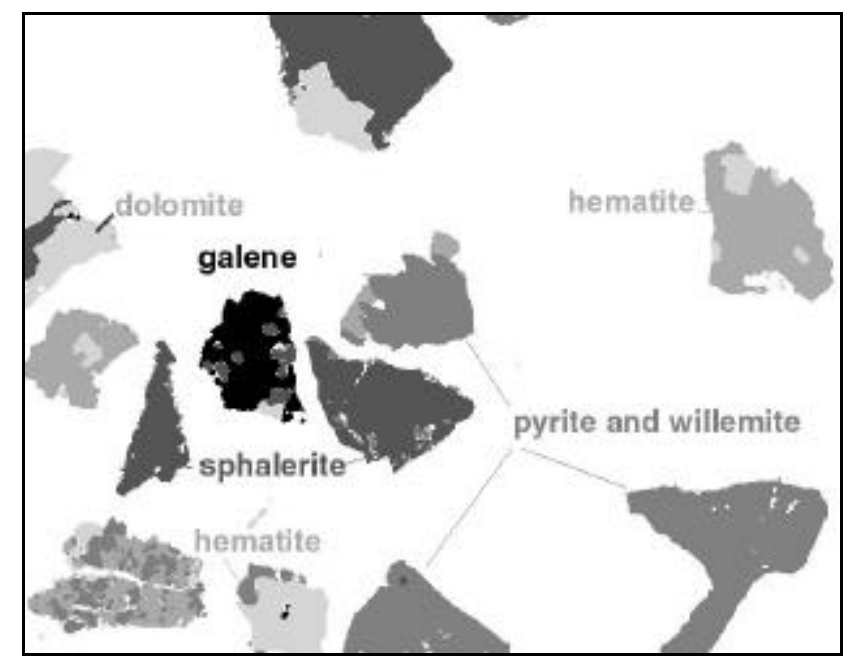

Fig. 3 - Superimposed binary images of the detected phases after processing the BSE image. Pyrite and wille mite, due to their close atomic numbers and complex intergrowths, were included in the same binary plane, as shown in Fig. 4. 


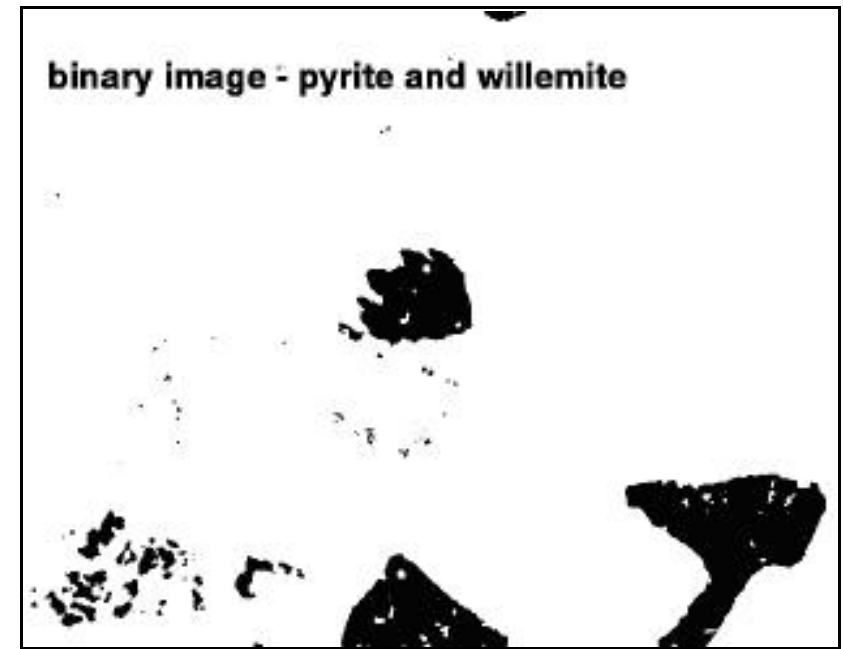

Fig. 4: Binary plane image of pyrite plus willemite

The acquired multi-element X-ray dot-mapping image was then submitted to a gray level threshold that was intended to discriminate the sulfur and zinc individual $\mathrm{X}$ ray binary images as shown in the Fig. 5 .

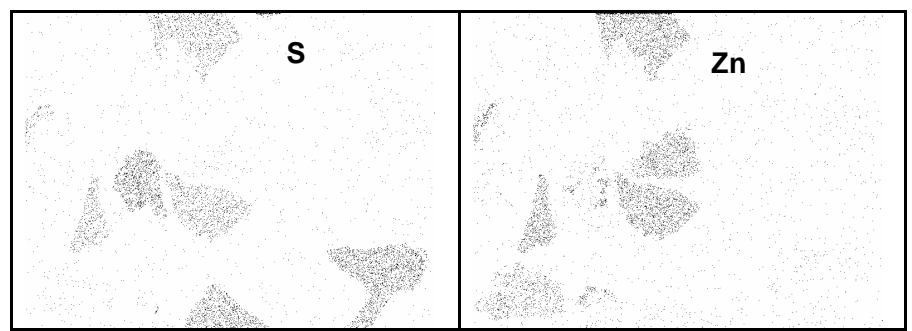

Fig. 5: Sulfur and zinc X-ray dot-mapping binary images after processing the multi-element X-ray dot image

Logic al operations with the "pyrite+willemite" binary image as a mask (Fig. 4) and X-ray dot images from S and Zn, Fig. 5, resulted in two others images representing $\mathrm{S}$ from pyrite and $\mathrm{Zn}$ from willemite, as showed in Fig. 6.

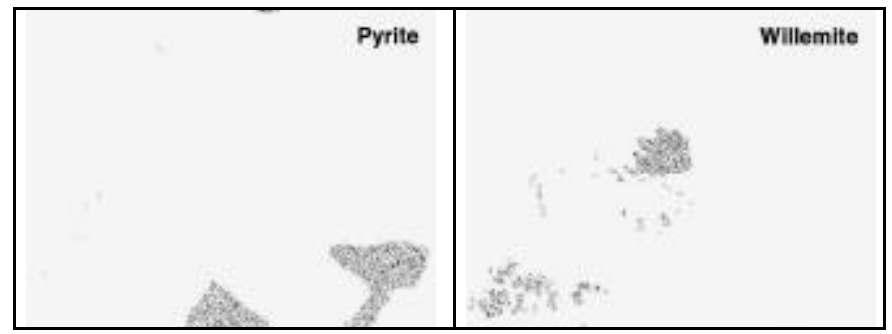

Fig. 6: Sulfur from pyrite and zinc from willemite after logical operations between "pyrite+willemite" binary image and X-ray dot images from $\mathrm{S}$ and $\mathrm{Zn}$ 
Further closing and logical operations allowed the segmentation between these two phases, as observed in Fig. 7.

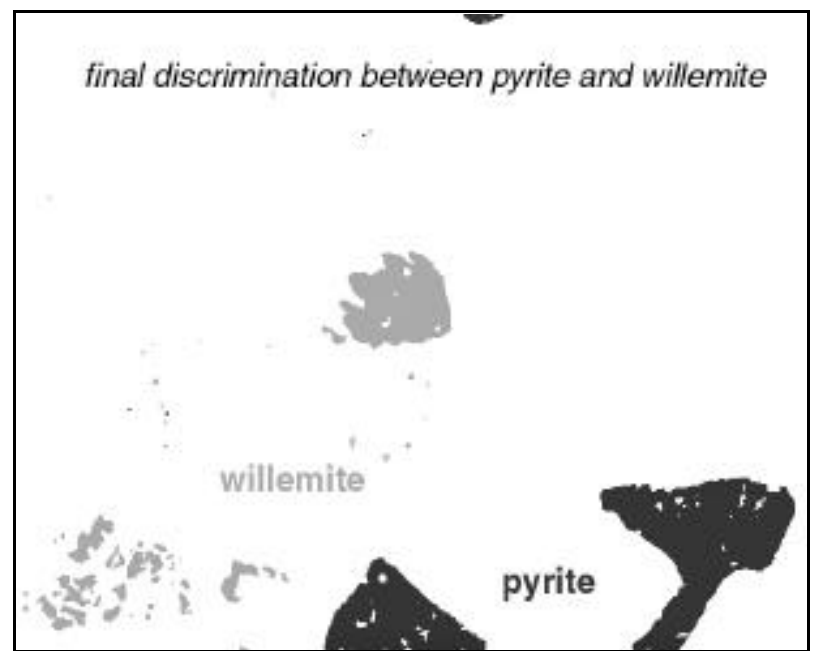

Fig. 7: Results of the final segmentation between pyrite and willemite after processing the gray level and X-ray dotmapping images

At the end of the segmentation procedure each mineral phase was represented by a binary image plane. Modal or quantitative phase analy sis could be then performed considering the area fraction measurements for the different binary planes (mineral phase). The results of all the 30 fields were accumulated in a file and, later on, normalized to $100 \%$ regarding the volume percentage. The weight percentages were attained considering the mineral densities and their volume fractions.

Liberation analyses of sphalerite and galena were performed by the liberation spectra technique. Feature measurements and a coincident parameter subroutine allowed he determination of the total area and the area fraction for each particle containing the valuable minerals. The particles containing sphalerite or galena were each subsequently and individually classified according to its area fraction and the results were expressed as cumulative curves compared to the amount of the valuable mineral phase (liberation spectra or potential recovery curves).

This procedure is not only the most suitable for the establishment of flexible criteria of free particles, but also gives important information regarding the distribution of locked particles. Stereological corrections for the liberation data from 2D to 3D were not applied to the attained results.

\section{Results}

The methodology above was applied to four closely screened size fractions. All the major mineral phases could be distinguished and quantified as the example exposed in Fig. 8 and by the results presented in Table 1. 


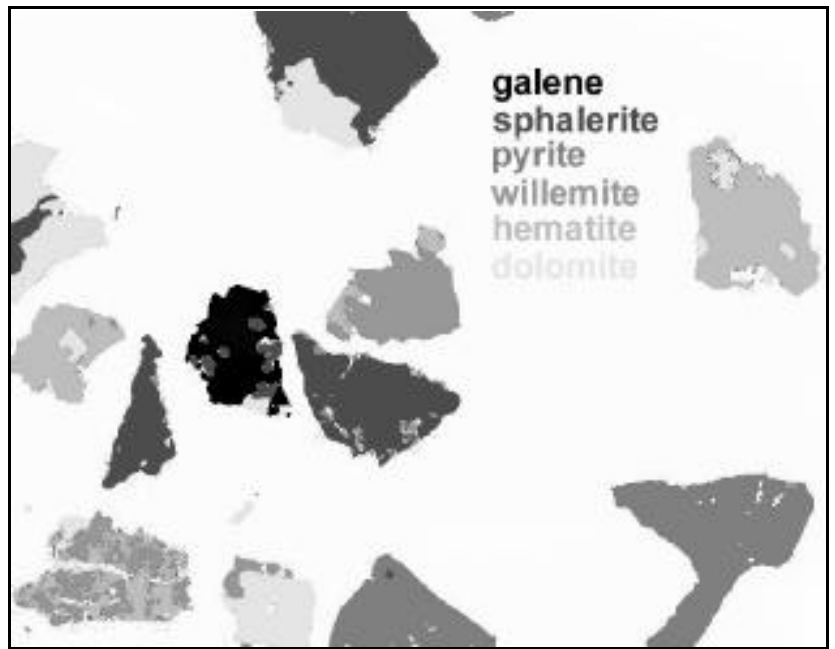

Fig. 8: Segmented mineral phases after image analysis processing

Table 1: Modal analysis results (weight percentage)

\begin{tabular}{|c|c|c|c|c|}
\hline \multirow{2}{*}{$\begin{array}{l}\text { Mineral } \\
\text { Phase }\end{array}$} & \multicolumn{4}{|c|}{ Size fraction } \\
\hline & $+44 \mu \mathrm{m}$ & $-44+37 \mu \mathrm{m}$ & $\begin{array}{l}-37 \\
+20 \mu \mathrm{m}\end{array}$ & $-20+10 \mu m$ \\
\hline sphalerite & 4.3 & 4.3 & 3.8 & 3.4 \\
\hline galena & 1.1 & 1.2 & 1.8 & 2.7 \\
\hline pyrite & 2.2 & 3.2 & 3.3 & 3.5 \\
\hline willemite & 2.6 & 2.3 & 2.5 & 1.7 \\
\hline hematite & 9.1 & 8.6 & 8.5 & 9.2 \\
\hline dolomite & 76.7 & 77 & 77 & 77 \\
\hline quartz & 4.0 & 3.6 & 3.3 & 2.6 \\
\hline others & $<1.0$ & $<1.0$ & $<1.0$ & $<1.0$ \\
\hline
\end{tabular}

Sphalerite, the major $\mathrm{Zn}$ bearing mineral, represents $3.8 \%$ in weigh and carries about $60 \%$ of the total zinc of the sample. EDS analysis showed minor contents of $\mathrm{Fe}$ and $\mathrm{Cd}$ associated with sphalerite, with an average grade of $0.6 \%$ in weigh for both elements. The average grain size of the sphalerite was between 10 and $20 \mu \mathrm{m}$. Willemite, $2.1 \%$ in weight, is an autigenic $\mathrm{Zn}$ bearing mineral related to the weathering process that carries almost $30 \%$ of the zinc content in the sample.

Galena, $1.8 \%$ in weight, is the only $\mathrm{Pb}$ bearing mineral. Two distinct generations could be identified; the first and coarsest one presents an average grain size of 30 to $40 \mu \mathrm{m}$. The other one, with grain sizes below $10 \mu \mathrm{m}$, is usually intergrown with sphalerite, willemite but seldom with dolomite.

Dolomite (and Zn-dolomite) is by far the major mineral in the sample, constituting $76 \%$ of the total in weight. Detailed SEM study showed that dolomite is partially recrystallized with incorporation of variable amounts of $\mathrm{Zn}$ and Fe. EDS analyses showed $\mathrm{ZnO}$ ranging from $0.4 \%$ up to more than $10 \%$, with an average grade of $4.9 \%$ of $\mathrm{ZnO}$, which means that $10 \%$ of the total $\mathrm{Zn}$ of the sample is related to dolomite. 
Mineral liberation spectra, demonstrated by both sphalerite and galena, are observed by Figs. 9 and 10, respectively.

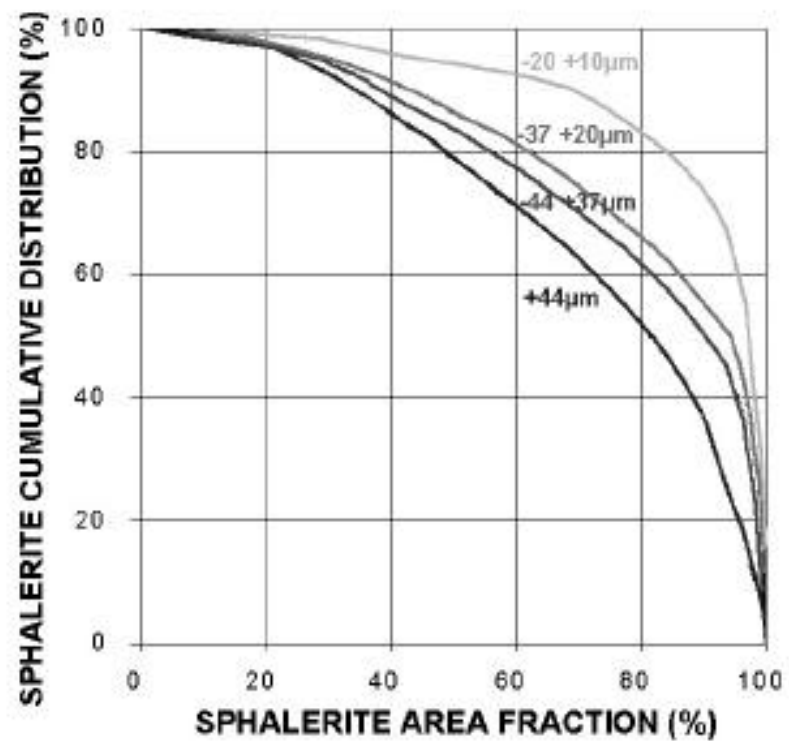

Fig. 9: Liberation spectra curves for sphalerite

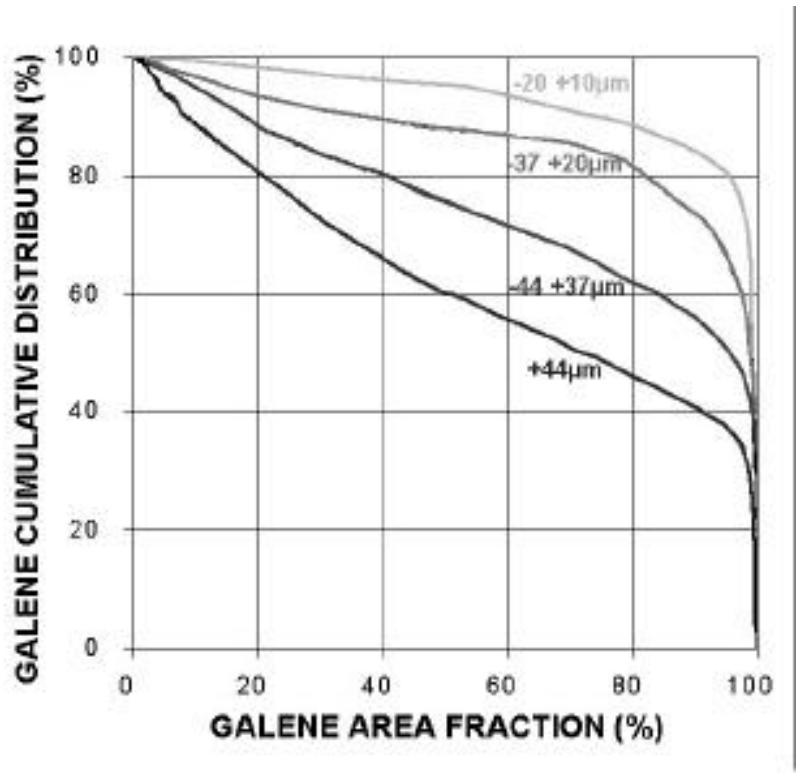

Fig. 10: Liberation spectra curves for gale na

To achieve relatively high grades and recoveries in mineral processing the valuable mineral must be individualized to almost monomineral particles by grinding operations prior to the physical concentration process. The valuable mineral content is directly related to the concentrate specifications, but, on average, it is acceptable for a $90 \%$ fraction of the valuable mineral to consider a particle as "free".

For the studied sample reasonable mineral liberation is attained only below $20 \mu \mathrm{m}$, which means that this type of ore must be ground in much a finer way than 
usual $(<44 \mu \mathrm{m})$. Potential recoveries of $85-90 \%$ for galena and $75-85 \%$ for sphalerite or $45-51 \%$ for $\mathrm{Zn}$ can be expected.

\section{Discussion}

An image analysis routine coupling BSE and X-ray dot-mapping images produced a proper mineral discrimination for quantitative phase and mineral liberation degree analysis. The data acquired for closely screened fractions sizes were extremely helpful for understanding the ore behavior and the optimization of the mineral dressing process. The study samples represented three $\mathrm{Zn}$ bearing minerals; sphalerite, the valuable $\mathrm{Zn}$ mineral, carries only $60 \%$ of the total $\mathrm{Zn}$ sample content. Liberation analysis showed that ore must be ground much finer than usual, minus $20 \mu \mathrm{m}$, to assure the required concentrate grades with reasonable mineral recoveries.

\section{References}

1. Gabas, S.G. Análise de Imagens Aplicada à Caracterização de Minérios - Análise Modal e Liberação. Dissertação de Mestrado, Escola Politécnica da Universidade de São Paulo (1999).

2. Kahn, H.; Sant'Agostino, L.; Mano, E.S., Tassinari, M.M. (1998) Acta Microscopica. 7-A: 241-244.

3. Lastra, R.; Petruk, W; Wilson, J. Image analysis techniques and applications to mineral processing. In: Modern approaches to ore and environmental mineralogy. Mineralogical Association of Canada. Short Course Series, V.27, p327-366 